\title{
Effects of Noncompetitive N-Methyl-D- Aspartate Receptor Antagonists on Opiate Tolerance and Physical Dependence
}

Keith A. Trujillo, Ph.D.

Recent research has demonstrated that $N$-methyl-Daspartate (NMDA) receptors, a class of excitatory amino acid receptors, may have an important role in opiate' tolerance and physical dependence. Much of the evidence for this has arisen from studies that have examined the effects of NMDA receptor antagonists on these phenomena. This article summarizes research from our laboratory on the effects of NMDA receptor antagonists on opiate tolerance and dependence in rats.

KEY WORDS: N-methyl-D-aspartate receptors; Opiate tolerance and dependence; MK-801; Dizocilpine;

Phencyclidine; Ketamine; Dextrorphan; Neuronal plasticity

Opiate tolerance and dependence are phenomena of considerable interest to the clinician, as well as the basic researcher. To the clinician, these phenomena represent complications in treatment of chronic pain and potential contributions to the street use of opiates. To the basic researcher, these phenomena represent elusive targets of understanding. Despite decades of study, there has yet to be an adequate understanding of the mechanisms leading to the development of tolerance and physical dependence.

Recent research, from our laboratory and others.

From the Psychology Program. California State University. San Marcos, California.

Address correspondence to: Keith A Irujillo, Ph.D., Psycholog,

Program. California State University, San Marcos, CA 92096.

Received December 12, 1994; revised Mav ร, 1995; accepted Mav 11, 1995.
Noncompetitive NMDA antagonists, including MK-801, ketamine, phencyclidine, and dextrorphan have been found at low doses to inhibit the development, or acquisition, of opiate tolerance and dependence but not the expression. The results suggest that NMDA receptors have a role in the neural plasticity responsible for tolerance and dependence. Selected theoretical and therapeutic implications of these findings are discussed. [Neuropsychopharmacology 13:301-307, 1995]

has provided evidence that $\mathrm{N}$-methyl-D-aspartate (NMDA) receptors, a class of excitatory amino acid receptors, may have an important role in the development of opiate tolerance and dependence. The idea that led us to initiate studies in this area was sparked by two independent observations. The first is that opiate tolerance and dependence are excellent examples of neural and behavioral plasticity. In other words, these phenomena are experience-dependent changes in behavior, presumably mediated by changes in neural systems. The second is that NMDA receptors appear to be involved in several different types of neural and behavioral plasticity, ranging from developmental processes to longterm potentiation and learning (Collingridge and Lester 1989; Collingridge and Singer 1990). These convergent observations led us to hypothesize that NMDA receptors might also be involved in the neural and behavioral plasticity resulting from long-term opiate administration. The prediction, based on this hypothesis, was that NMDA receptor antagonists should inhibit the development of opiate tolerance and physical dependence. 

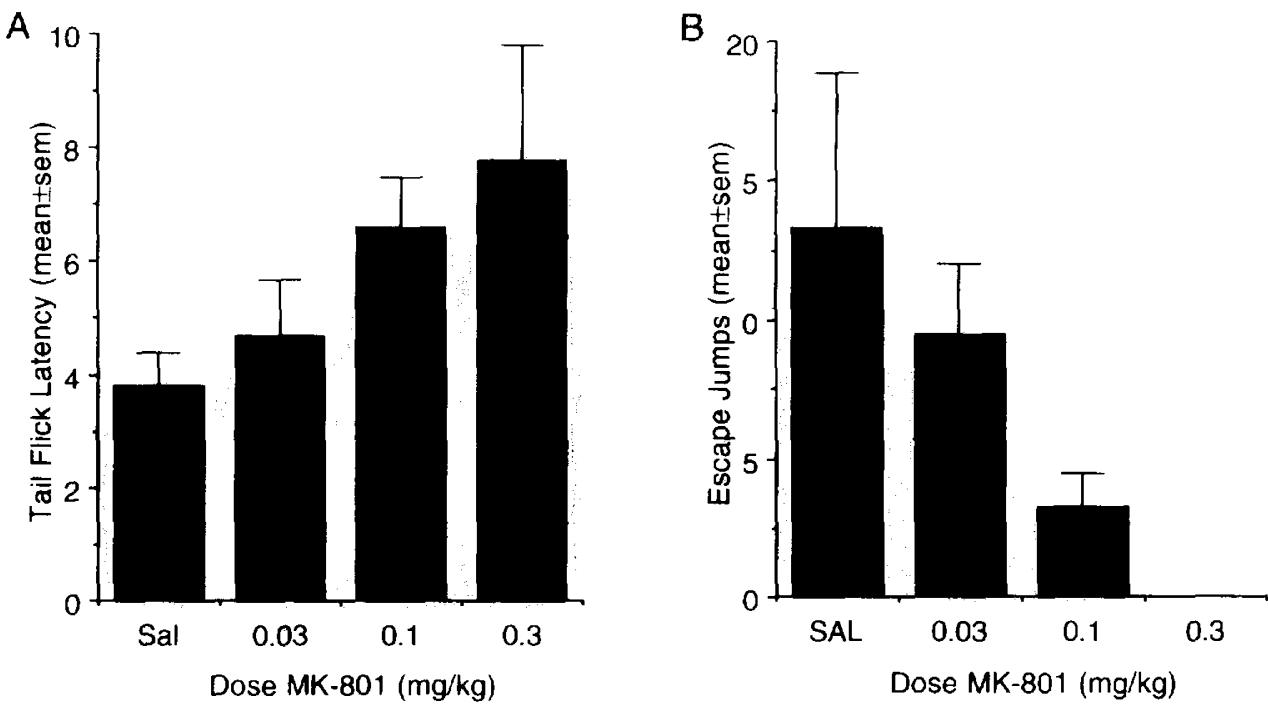

Figure 1. Inhibition of the development of morphine tolerance and dependence by MK-801. Adult male Sprague-Dawley rats received an injection of saline or MK-801 $(0.1$ to $0.3 \mathrm{mg} / \mathrm{kg})$, followed 30 minutes later by an injection of morphine (10 $\mathrm{mg} / \mathrm{kg}$ ), twice daily for 9 days. On day 10 the animals received morphine in the absence of saline or MK-801. (A) MK-801 inhibited the development of tolerance, as demonstrated by the increased antinociception on day 10 in animals that had previously been treated with this drug. (B) MK-801 inhibited the development of physical dependence, as demonstrated by decreased naloxone-induced escape-jumping on day 10. Redrawn from Trujillo and Akil (1991a). Copyright 1991 by the AAAS.

It is important to emphasize the focus on the devel opment, rather than the expression of these phenomena. If NMDA receptors are selectively involved in the neural and behavioral plasticity responsible for tolerance and dependence, then they should inhibit the development. or acquisition, of these phenomena, but not the expression. In other words, they should be effective when coadministered with opiates as tolerance and dependence are acquired, but should be ineffective when administered acutely to a subject that is already tolerant and dependent.

This article includes a synopsis of our findings on the potential role of NMDA receptors in the behavioral consequences of long-term opiate administration and covers four topics related to this area: (1) the effect of noncompetitive NMDA receptor antagonists on the development of opiate tolerance and dependence; (2) the potential role of learning in the ability of NMDA antagonists to inhibit these phenomena; (3) the localization within the nervous system for the effects of NMDA antagonists; and (4) the effects of these drugs on the ex pression of the opiate withdrawal syndrome. Each of these lines of research is discussed later, together with comments on the potential theoretical and clinical relevance of the findings, and a perspective on future avenues for research. It should be noted that although the focus of this study is on the potential role of NMDA receptors in opiate tolerance and dependence, this is not to imply that this is the only neurotransmitter system involved in these phenomena. For information about the potential involvement of other svstems in opiate toler- ance and dependence, see previous reviews (Cox and Werling 1991; Martin and Sloan 1977; Redmond and Krystal 1984; Trujillo and Akil 1991c).

\section{EFFECTS OF MK-801}

We began this area of research by examining the effect of MK-801, a potent and selective noncompetitive NMDA receptor antagonist, on opiate tolerance and physical dependence in rats (Trujillo and Akil 1990; Trujillo and Akil 1991a). We found that a very low dose of this drug had the ability to inhibit the development, but not the expression, of tolerance to morphine antinociception, without affecting pain responsiveness on its own and without altering the acute antinociceptive actions of morphine. Moreover, this drug had the ability to inhibit the development, but not the expression of physical dependence on morphine (Figure 1).

The findings on the ability of MK-801 to inhibit opiate tolerance have been replicated by several different laboratories (Ben-Eliyahu et al. 1992; Bhargava and Matwyshyn 1993; Elliott et al. 1994; Gutstein and Trujillo 1993; Kest et al. 1993; Lutfy et al. 1993; Marek et al. 1991; Tiseo and Inturrisi 1993; Trujillo and Akil 1994). There is almost universal agreement from these studies that NMDA receptor antagonists inhibit the development of tolerance to the antinociceptive actions of morphine. Recently, Shoemaker, Kosten, and Muly (Shoemaker et al, in press) replicated and extended our findings on 


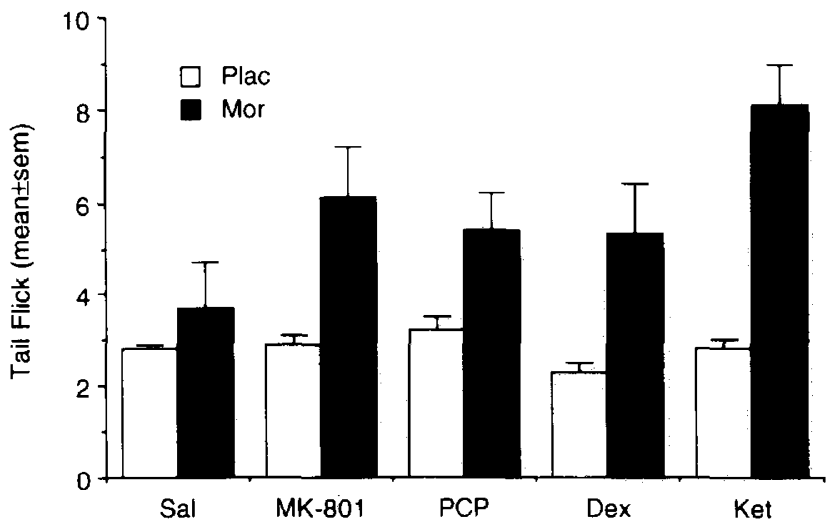

Figure 2. Inhibition of the development of morphine tolerance by the noncompetitive NMDA receptor antagonists MK801, phencyclidine (PCP), dextrorphan (DEX), and ketamine (Ket). Adult male Sprague-Dawley rats were implanted with a single morphine pellet (Mor) or placebo pellet (Plac) and an osmotic mini-pump delivering saline (Sal), MK-801 (0.1 $\mathrm{mg} / \mathrm{kg} /$ day $),$ PCP $(1.0 \mathrm{mg} / \mathrm{kg} / \mathrm{day})$, Dex $(5.0 \mathrm{mg} / \mathrm{kg} / \mathrm{day})$, or Ket $(10 \mathrm{mg} / \mathrm{kg} /$ day). Each of the NMDA receptor antagonists inhibited the development of morphine tolerance as demonstrated by increased antinciception, relative to control animals, 72 hours after implant. Redrawn from Trujillo and Akil (1994).

the ability of NMDA receptor blockade to inhibit the development of morphine physical dependence. The ability of NMDA antagonists to inhibit the development, but not the expression of opiate tolerance and dependence is unique among drugs that have been found to affect these phenomena. These results support the hypothesis that NMDA receptors are involved in the neural plasticity resulting from long-term opiate administration.

\section{OTHER NONCOMPETITIVE NMDA RECEPTOR ANTAGONISTS}

Despite the many demonstrations of significant inhibition of opiate tolerance and physical dependence by MK-801, in order to more strongly demonstrate an involvement of NMDA receptors, it is necessary to show a similar effect with other NMDA antagonists. We recently reported that in addition to MK-801, the noncompetitive NMDA antagonists phencyclidine, ketamine and dextrorphan each had the ability to inhibit the development of opiate tolerance (Figure 2; Trujillo and Akil 1994). Importantly, the doses found to inhibit tolerance paralleled the potency of these drugs at the NMDA receptor. Similar findings have also been reported for competitive NMDA receptor antagonists (see the articles by Inturrisi, Elliott, and Pasternak in this issue). The fact that several different NMDA receptor antagonists produce similar effects on the develop- ment of opiate tolerance demonstrates that this action is not the "side-effect" of a particular drug, but a general action of NMDA receptor blockers.

The ability of the individual noncompetitive NMDA receptor antagonists to inhibit the development of opiate tolerance raises some interesting points for discussion. For example, the fact that a well-known drug of abuse, phencyclidine, can inhibit tolerance to opiates, raises the possibility that addicts may have discovered the potential of this combination in the street use of the drugs. However, despite the fact that polydrug abuse is a common phenomenon among street users, we have been unable to find any reports of significant use of phencyclidine and opiates in combination. It is quite possible that the combination has indeed been tried, but that untoward side-effects of the two drugs in combination prevented further use (see Trujillo and Akil 1991b).

The effectiveness of dextrorphan in inhibiting the development of opiate tolerance raises a very intriguing possibility. This is that the racemic mixture of dextrorphan (or its structural analogue dextromethorphan), together with the levorotatory enantiomer levorphanol, a potent opiate analgesic, may be a more effective treatment for chronic pain than the resolved opiate. The results of our studies suggest that the racemic mixture would have potent analgesic properties from the levorotatory opiate, but that tolerance would be inhibited by the dextrorotatory NMDA receptor antagonist. Future experiments should be aimed at testing various combinations of dextrorphan and levorphanol for a ratio that produces potent pain relief, but in which the development of tolerance is effectively inhibited.

Considering therapeutic potential, perhaps the most interesting drug examined is ketamine. This drug, at relatively high doses produces both analgesia and anesthesia and has been used clinically for both of these purposes (Domino 1990; Gutstein et al. 1992; White et al. 1982). Its use, however, has been somewhat limited by the tendency of this drug to produce psychotimimetic effects at moderate to high doses (Domino 1990; Gutstein et al. 1992; Krystal et al. 1994; White et al. 1982). The results from our laboratory demonstrate that ketamine has the ability to inhibit the development of tolerance to morphine antinociception in rats at doses well below those that produce antinociception, anesthesia, or motor debilitation (Trujillo and Akil 1994). Translating this to potential human use, the effective dose of ketamine for inhibiting opiate tolerance may be well below that at which psychotimimetic effects occur.

\section{THE POTENTIAL INVOLVEMENT OF LEARNING}

Psychopharmacologic research has demonstrated an important role for learning in the development of opi- 
ate tolerance under the appropriate experimental conditions. Tolerance that develops as a result of learned associations between drug effects and environmental cues is known as associative, or behavioral, tolerance. In contrast, tolerance that develops from more direct physiologic adaptations in response to the drug treatment is known as nonassociative, or pharmacologic, tolerance (Poulos and Cappell 1991; Siegel 1990; Stewart and Badiani 1993; Trujillo and Akil 1991c; Trujillo and Akil 1995). As noted earlier, NMDA receptor antagonists have been reported to interfere with some types of learning. As such, the question arose early in the course of our experiments as to whether NMDA antagonists inhibit the development of opiate tolerance directly, by interfering with the neural plasticity responsible for nonassociative tolerance, or if they might act indirectly, by interfering with the learning known to be involved in the development of associative tolerance (Trujillo and Akil 1991a; Trujillo and Akil 1991c).

Experiments performed in our laboratory (Gutstein and Trujillo 1993; Trujillo and Akil 1994), as well as in others (Ben-Eliyahu et al. 1992; Marek et al. 1991), have addressed this question and all have arrived at the same conclusion: NMDA receptor antagonists have the ability to potently inhibit nonassociative opiate tolerance. Moreover, data from our laboratory suggest that these drugs may not have the ability to inhibit associative tolerance (Trujillo and Akil 1994). These results suggest that learning factors are not involved in the ability of NMDA antagonists to interfere with opiate tolerance. It therefore appears that these drugs act more directly on the neural mechanisms responsible for the development of tolerance to opiate analgesia.

\section{LOCALIZATION}

In order to obtain a more complete picture of the role of NMDA receptors in opiate tolerance and dependence, we initiated studies aimed at addressing the potential sites of action for these drugs, beginning with the spinal cord (Gutstein and Trujillo 1993; Gutstein et al. 1992). In these experiments we took advantage of the fact that the tail-flick response, which is used to follow the development of tolerance to opiate antinociception, survives spinal transection. Opiates inhibit the tail-flick response in spinally transected rats, and the effect of morphine shows tolerance with chronic administration. This preparation is therefore ideal for examining the effects of morphine in the spinal cord, in the absence of descending influence from the brain. In these experiments, MK- 801 was found to inhibit the development of tolerance to morphine antinociception in spinally transected animals without affecting pain responsiveness on its own (Gutstein and Trujillo 1993; Gutstein et al. 1992). These findings, which were nearly identical to those of similar experiments performed in animals with an intact spinal cord (Trujillo and Akil 1994), suggest that the spinal cord is an important locus of action for the inhibition of opiate tolerance by NMDA receptor antagonists. Using intrathecal injections, Kest and co-workers similarly reported that NMDA antagonists have the ability to inhibit opiate tolerance at the spinal level (Kest et al. 1993). Although these studies do not eliminate a potential role for NMDA receptors outside of the spinal cord in the development of opiate tolerance, they strongly suggest that actions of NMDA receptor antagonists at the spinal level are sufficient to inhibit tolerance to the antinociceptive actions of morphine.

It is important to add that the findings in spinally transected rats provide perhaps the strongest evidence that learning factors are not involved in the inhibition of tolerance by NMDA receptor antagonists (Gutstein and Trujillo 1993; Gutstein et al. 1992). In these animals the tail-flick reflex was isolated from neural connections with the brain. As such, environmental cues had no neural access to the site at which tolerance was assessed (the lower spinal cord). Because the development of associative tolerance is dependent upon environmental input, the ability of MK-801 to inhibit the development of tolerance in spinally transected animals strongly argues that associative learning is not involved.

\section{DO NMDA RECEPTOR ANTAGONISTS BLOCK THE OPIATE WITHDRAWAL SYNDROME?}

Our initial experiments on the effects of MK-801 on opiate physical dependence demonstrated that this drug was effective at inhibiting signs of opiate withdrawal when it was coadministered with morphine during chronic treatment, but it was ineffective when administered acutely to an animal immediately prior to naloxone-precipitated withdrawal (Trujillo and Akil 1990; Trujillo and Akil 1991a). These findings suggest that NMDA receptors are involved in the development, but not the expression of physical dependence. However, several investigators have reported that NMDA receptor antagonists have the ability to inhibit the $e x$ pression of physical dependence (Brent and Chahl 1993; Cappendijk et al. 1993; Higgins et al. 1992; Koyuncuoglu et al. 1992; Koyuncuoglu et al. 1990; Koyuncuoglu and Saydam 1990; Rasmussen et al. 1991a; Rasmussen et al. 1991b; Tanganelli et al. 1992). A close examination of the latter findings reveals that the NMDA antagonists typically inhibit the expression of withdrawal at doses that produce confounding effects, such as motor debilitation. This observation led us to speculate that the primary effect of NMDA antagonists on the expression of physical dependence is not a selec- 
tive inhibition of this phenomenon, but instead the result of behavioral competition between the acute motoric effects of the antagonists and the opiate withdrawal syndrome. Recent experiments, in which we found a highly significant correlation between the motoric effects of MK-801 and the ability of this drug to inhibit withdrawal, support this speculation (Trujillo and Akil 1993; Trujillo and Akil 1995). We therefore have concerns about the potential involvement of NMDA receptors in the expression of the opiate withdrawal syndrome. It needs to be noted that MK- 801 and the other NMDA receptor antagonists suppress the development of morphine tolerance and physical dependence at doses below those that produce motor debilitation. Thus, although we believe that there is strong evidence that NMDA receptors are involved in the development of physical dependence, further research is necessary to definitively demonstrate a role for these receptors in the expression of this phenomenon (see Trujillo and Akil 1995 for further discussion).

The interest in this controversy arises not only from the potential theoretical impact, but also because of the important clinical implications. If it can be demonstrated that NMDA receptor antagonists selectively block the expression of the opiate withdrawal syndrome, then there is promise for these drugs in the detoxification of opiate addicts. On the other hand, if these antagonists are found to interfere with the expression of withdrawal primarily through behavioral competition, then these drugs will likely be ineffective in detoxification. Further research, both in animals and humans, will help to clarify this controversy. In this regard, intriguing preliminary findings from Koyuncuoglu and Saydam (1990) suggest that the noncompetitive NMDA antagonist dextromethorphan may indeed have the ability to alleviate some symptoms of withdrawal in humans.

\section{CONCLUSIONS}

The studies summarized in this article represent only a portion of the research that has investigated the potential role of NMDA receptors in opiate tolerance and dependence. Other work in this area is described in other articles in this issue of Neuropsychopharmacology, and in a more comprehensive review published elsewhere (Trujillo and Akil in press). Taken together, the results of these studies provide overwhelming evidence that NMDA receptors have an important role in opiate tolerance and physical dependence. The majority of results demonstrate that low doses of NMDA receptor antagonists inhibit the development, but not the expression of these phenomena, without affecting acute opiate actions. The results are therefore consistent with the hypothesis that NMDA receptors are involved in the neural and behavioral plasticity responsible for the de- velopment of tolerance and dependence. This role is unique among the many neurotransmitter systems that have been examined for involvement in the actions of opiates. Whereas other neurotransmitters have been found to modulate various opiate effects, none appear to be selectively involved in the development of tolerance and dependence.

Despite numerous studies on this topic over the past 4 to 5 years, many questions remain unanswered about the role of NMDA receptors in opiate tolerance and dependence. Future research will undoubtedly be aimed at a variety of levels, ranging from the cellular and molecular to the clinical, in order to more clearly understand the involvement of these receptors.

Most of the work to date on the involvement of NMDA receptors in opiate tolerance and dependence has focused on selected behavioral measures in the whole animal. Because of the focus on behavioral measures, little is known about the basic mechanisms responsible for the interaction between NMDA receptors and opiates. For example, it is presently unknown whether this interaction occurs at the level of individual neurons, at the level of simple interactions between neurons, or if it involves more complex circuitry. The finding that the intercellular messenger nitric oxide may mediate some of the actions of NMDA receptors in tolerance and dependence (see the article by Pasternak in this issue) suggests that communication between adjacent neurons may be important in the development of these phenomena. Determining the specific cellular and molecular mechanisms responsible for the interactions between NMDA receptors and opiates will be an important focus for future research, and will provide for a clearer understanding of the physiologic basis for tolerance and dependence.

Because research on NMDA receptor involvement in opiate tolerance has focused almost exclusively on antinociception, it is unknown whether these receptors are involved in tolerance to other opiate actions. Tolerance may develop via multiple mechanisms, only one of which may involve NMDA receptors (Trujillo and Akil 1991c; Trujillo and Akil 1995). It would therefore be surprising if all examples of opiate tolerance were found to be inhibited by NMDA receptor antagonists. Incidental observations in our laboratory suggest that these antagonists may inhibit tolerance to the locomotor depressant effects of opiates (Trujillo and Akil 1994). On the other hand, Bhargava and Matwyshyn (1993) have reported that NMDA antagonists do not interfere with tolerance to the hyperthermic effects of opiates. Research aimed at determining the effect of NMDA receptor antagonists on different physiologic and behavioral measures of opiate tolerance and dependence will provide important clues to the role of NMDA receptors in opiate-induced neural and behavioral plasticity.

There are differing ideas regarding the clinical 
potential of NMDA receptor antagonists in opiate tolerance and dependence. As noted earlier, although some believe that these antagonists may be effective in treat ing acute opiate withdrawal, we do not feel that this has been adequately demonstrated in animal models. Given the results of animal studies, we believe that the most immediate clinical potential for NMDA receptor antagonists lies in their use as adjuncts to opiates in the management of chronic pain. Because of the ability of NMDA antagonists to inhibit the development of tolerance, preparations containing an NMDA antagonist and an opiate should provide longer-lasting analgesia than the opiate alone during chronic administration. This possibility provides an interesting twist to research in the opiate field. For years pharmacologists have searched without success for an opiate that produces potent analgesia but that does not produce tolerance and dependence. The results summarized here suggest that a better approach may be to administer an adjunct, such as an NMDA antagonist, which allows the opiate to retain its full analgesic effect, but that inhibits the development of tolerance and dependence (Trujillo and Akil 1994).

Of considerable relevance and interest to the present discussion are findings on the role of NMDA receptors in neural and behavioral plasticity from other drugs. Evidence suggests that these receptors may have an important role in tolerance, sensitization, and physical dependence seen following administration of several other psychoactive drugs, including amphetamine, cocaine, nicotine, ethanol, and antidepressants (see Trujillo and Akil 1995). Future research should examine the parallels between the long-term effects of these drugs, in order to gain a better understanding of the basic mechanisms underlying the involvement of NMDA receptors in neural and behavioral plasticity and the clinical potential for NMDA receptor antagonists in psychiatry and neurology.

\section{ACKNOWLEDGMENTS}

The research described in this article was performed in the laboratory of Dr. Huda Akil at the University of Michigan. She was an integral part of all of this work, providing important intellectual contributions and unwavering support (both material and otherwise). I am very grateful for the kindness, generosity, and support she offered throughout my tenure in her laboratory. I would like to thank Dr. Barbara Herman of the National Institute on Drug Abuse for organizing the Technical Review at which this work was presented and for inviting me to participate. This research was supported by the T. Raphael Research Fund, the Lucille B. Markey Charitable Fund, and Grant DA02265 from the National Institute on Drug Abuse. The author is the recipient of a Young Investigator Award from the National Alliance for Research on Schizophrenia and Depression (NARSAD).

\section{REFERENCES}

Ben-Eliyahu S, Marek P, Vaccarino AL, Mogil JS, Sternberg WF, Liebeskind JC (1992): The NMDA receptor antagonist MK-801 prevents long-lasting nonassociative morphine tolerance in the rat. Brain Research 575:304-308

Bhargava HN, Matwyshyn GA (1993): Dizocilpine (MK-801) blocks tolerance to the analgesic but not to the hyperthermic effect of morphine in the rat. Pharmacology $47: 344-350$

Brent PJ, Chahl LA (1993): Enhancement of the opiate withdrawal response by antipsychotic drugs in guinea pigs is not mediated by sigma binding sites. Eur Neuropsychopharmacol 3:23-32

Cappendijk SLT, de Vries R, Dzoljic MR (1993): Excitatory amino acid receptor antagonists and naloxone-precipitated withdrawal syndrome in morphine-dependent mice. Eur Neuropsychopharmacol 3:111-116

Collingridge GL, Lester RAJ (1989): Excitatory amino acid receptors in the vertebrate central nervous system. Pharmacol Rev 41:143-210

Collingridge GL, Singer W (1990): Excitatory amino acids and synaptic plasticity. Trends Pharmacol Sci 11:290-296

Cox BM, Werling LL (1991): Opioid tolerance and dependence. In Pratt JA (ed), The Biological Basis of Drug Tolerance and Dependence. San Diego, Academic Press, pp 199-229

Domino EF (1990): Status of Ketamine in Anesthesiology. Ann Arbor, MI, NPP Books.

Elliott K, Minami N, Kolesnikov YA, Pasternak GW, Inturrisi CE (1994): The NMDA receptor antagonists, LY274614 and MK-801, and the nitric oxide synthase inhibitor, NGnitro-L-arginine, attenuate analgesic tolerance to the muopioid morphine but not to kapa opioids. Pain 56:69-75

Gutstein HB, Johnson KL, Heard MB, Gregory GA (1992): Oral ketamine preanesthetic medication in children. Anesthesiology 76:28-33

Gutstein HB, Trujillo KA (1993): MK-801 inhibits the development of morphine tolerance at spinal sites. Brain Res $626: 332-334$

Gutstein HB, Trujillo KA, Akil H (1992): Does MK-801 inhibit the development of morphine tolerance in the rat at spinal sites? Anesthesiology 77:A737

Higgins GA, Nguyen P, Sellers EM (1992): The NMDA antagonist dizocilpine (MK-801) attenuates motivational as well as somatic aspects of naloxone precipitated opioid withdrawal. Life Sci 50:PL167-172

Kest B, Mogil JS, Shamgar B-E, Kao B, Liebeskind JC, Marek $P$ (1993): The NMDA receptor antagonist MK-801 protects against the development of morphine tolerance after intrathecal administration. Proc West Pharmacol Soc $36: 307-310$

Koyuncuoglu H, Dizdar Y, Aricioglu F, Sayin U (1992): Effects of MK-801 on morphine physical dependence: Attenuation and intensification. Pharmacol Biochem Behav 43: 487-490

Koyuncuoglu H, Gungor M, Sagduyu H, Aricioglu F (1990): Suppression by ketamine and dextromethorphan of precipitated abstinence syndrome in rats. Pharmacol Biochem Behav 35:829-832 
Koyuncuoglu H, Saydam B (1990): The treatment of heroin addicts with dextromethorphan. A double-blind comparison of dextromethorphan with chlorpromazine. Int J Clin Pharmacol Ther Toxicol 28: 147-452

Krystal JH, Karper LP, Seibyl JP, Freeman GK, Delaney R, Bremner JD, Heninger GR, Bowers MB, Charney DS (1994): Subanesthetic effects of the noncompetitive NMDA antagonist, ketamine, in humans: Psychotomimetic, perceptual, cognitive and neuroendocrine responses. Arch Gen Psychiatry 51:199-214

Lutfy K, Hurlbut DE, Weber E (1993): Blockade of morphineinduced analgesia and tolerance in mice by MK- 801 . Brain Res 616:83-88

Marek P, Ben-Eliyahu S, Vaccarino AL, Liebeskind JC (1991): Delayed application of MK-801 attenuates development of morphine tolerance in rats. Brain Res 558:163-165

Martin WR, Sloan JW (1977): Neuropharmacology and neurochemistry of subjective effects, analgesia, tolerance, and dependence produced by narcotic analgesics. In Martin WR (ed), Handbook of Experimental Pharmacology, Vol 45/I. Drug Addiction I: Morphine, Sedative/Hypnotic and Alcohol Dependence. New York, Springer-Verlag, pp 43-158

Poulos CX, Cappell H (1991): Homeostatic theory of drug tolerance: A general model of physiologic adaptation. Psychol Rev 98:390-408

Rasmussen K, Fuller RW, Stockton ME, Perry KW, Swinford RM, Ornstein PL (1991a): NMDA receptor antagonists suppress behaviors but not norepinephrine turnover or locus coeruleus unit activity induced by opiate withdrawal. Eur J Pharmacol 197:9-16

Rasmussen K, Krystal JH, Aghajanian GK (1991b): Excitatory amino acids and morphine withdrawal: Differential effects of central and peripheral kynurenic acid administration. Psychopharmacology 105:508-512

Redmond DEJ, Krystal JH (1984): Multiple mechanisms of withdrawal from opioid drugs. Ann Rev Neurosci $7: 443-478$

Shoemaker WI, Kosten T, Muly S (in press): Ethanol attenu- ation of morphine addiction: Comparison to MK-801. Alcoholism: Clin Exp Res

Siegel S (1990): Classical conditioning and opiate tolerance and withdrawal. In Balfour DKJ (ed), Psychotropic Drugs of Abuse. New York, Pergamon, pp 59-85

Stewart I, Badiani A (1993): Tolerance and sensitization to the behavioral effects of drugs. Behav Pharmacol 4: 289-312

Tanganelli S, Antonelli T, Morari M, Bianchi C, Beani L (1991): Glutamate antagonists prevent morphine withdrawal in mice and guinea pigs. Neurosci Lett 122:270-272

Tiseo PJ, Inturrisi CE (1993): Attenuation and reversal of morphine tolerance by the competitive N-methyl-D-aspartate receptor antagonist LY274614. J Pharmacol Exp Ther $264: 1,090-1,096$

Trujillo KA, Akil H (1990): Behavioral interactions between morphine and MK-801: Analgesia, tolerance, dependence, and lethality. Soc Neurosci Abstr 16:211

Trujillo KA, Akil H (1991a): Inhibition of morphine tolerance and dependence by the NMDA receptor antagonist MK801. Science 251:85-87

Trujillo KA, Akil H (1991b): The NMDA receptor antagonist MK-801 increases morphine catalepsy and lethality. Pharmacol Biochem Behav 38:673-675

Trujillo KA, Akil H (1991c): Opiate tolerance and dependence: Recent findings and synthesis. New Biol 3:915-923

Trujillo KA, Akil H (1993): Does MK-801 block naloxoneprecipitated opiate withdrawal? Soc Neurosci Abstr $19: 1,246$

Trujillo KA, Akil H (1994): Inhibition of opiate tolerance by noncompetitive $\mathrm{N}$-methyl-D-aspartate receptor antagonists. Brain Res 633:178-188

Trujillo KA, Akil H (1995): Excitatory amino acids and drugs of abuse: A role of $\mathrm{N}$-methyl-D-aspartate receptors in drug tolerance, sensitization and physical dependence. Drug and Alcohol Dependence 38:139-154

White PF, Way WL, Trevor AJ (1982): Ketamine-Its pharmacology and therapeutic uses. Anesthesiology 56: $119-136$ 